\title{
Institutional Racism in Mental Health Services: The consequences of compromised conceptualisation
}

\author{
by Hannah Bradby \\ University of Warwick \\ Sociological Research Online, 15 (3) 8 \\ $<$ http://uww.socresonline.org.uk/15/3/8.html> \\ $10.5153 /$ sro. 2197
}

Received: 15 Dec 2009 Accepted: 3 Aug 2010 Published: 31 Aug 2010

\begin{abstract}
Inequalities in mental health service use and outcome in the British NHS have been attributed to institutional racism. Institutional racism is widely understood in terms of the definition published in the Macpherson report, despite critique of its inability to differentiate the role of individual and institution in discrimination, and weakness in distinguishing racism from other forms of discrimination. The inquiry into David Bennett's death declared the NHS to be institutionally racist, and, although still contested, this has been widely accepted. Poor conceptualisation and the endemic failure to demonstrate how institutional racism leads to iniquitous outcomes can be seen in recommendations to tackle it through individual education. Policy based on a compromised conceptualisation of institutional racism is unlikely to reduce racialised inequalities and, in the face of progress for ethnic minorities else-where, may lead to the conclusion that discrimination is no longer a problem. In the light of recent shifts in what is implied by institutional racism, suggestions for research towards a re-conceptualisation are made.
\end{abstract}

\section{Keywords: Health Services, Mental Health, Institutional Racism, Racism, Race}

\section{Introduction}

1.1 Barack Obama's US election victory was accompanied by claims that the shattering of institutional barriers marked the end of institutional racism. The arrival of an African American first family in the White House, built by Black slaves (among others) just over 200 years ago, was poignant. Nonetheless, the singular triumph of a Black junior senator does not wipe out systems of discrimination that can be seen in terms of racialised inequities in mortality and morbidity rates, access to health services, education and employment in the US as in the UK. Obama's election reinforces the American ideal that in the land of the free there is no systematic barrier to realising one's dreams, including aspiration to the highest office of the land. Reinforcing dreams is not the same as ensuring that social justice prevails and while Obama's presidency may yet have an effect on equalising access to health care ${ }^{[1]}$, its effect on discourse around institutional racism is harder to judge. This paper describes the origins of the term institutional racism and its widespread use in UK public service settings after the publication of two official investigations concerning the deaths of Black men. The Macpherson (1999) report examined the Metropolitan Police investigation of the murder of Stephen Lawrence and the Blofeld report (Norfolk, Suffolk and Cambridgeshire Strategic Health Authority 2003) considered the death of David Bennett in a mental health unit. Investigations of racism around a man's death are appalling but rare. A more usual context for discussing institutional racism is everyday injustice such as inequalities in service provision, service use, and in the outcomes of the service. Since the publication of the Macpherson report institutional racism has been declared to be a problem in the UK National Health Service (NHS) by officially sanctioned sources (e.g. Sashidharan 2003). This recognition of institutional racism represents a triumph for those who campaigned to get the circumstances of the deaths of Lawrence and of Bennett scrutinised, but also raises significant problems for combating racism. The declaration that the NHS is institutionally racist forecloses debate about racism in public services, despite the absence of good theoretical models or robust research evidence to show how it works. Relying on inequitable health outcomes and measures of experience of services means that institutional racism remains a 'black box' in terms of its function. In the highly charged debate about racism and mental health, there is little room for theoretical discussion. This paper relates the intractable nature of debates around institutional racism and mental health to the contradictions of the influential findings made by the Macpherson and Blofeld reports. A close reading of both reports, with particular attention to their stated and working definitions of racism and their recommendations is related to how these aspects of the reports were interpreted in public discourse after their publication. In particular, policy and commentary on 
mental health policy is related to the contradictions in the reports' definitions to illuminate conceptual gaps that might be impeding the current development of innovative initiatives to address racialist inequalities.

\section{Background}

2.1 The distinction between individual and institutional racism arose with the Black power movement in the US when it was described as subtle and less identifiable compared with individual racism. 'Respectable' individuals can absolve themselves from blame for individually racist acts but nonetheless 'support officials and institutions that perpetuate institutionally racist policies' (Carmichael and Hamilton 1967: 21). Institutional racism is used interchangeably with colonialism in pursuit of Carmichael and Hamilton's thesis that Black people in the US formed a colony exploited by White people. Their analysis established the oppression and exploitation of Black people as part of the structural organisation of society, rather than a problem that could be tackled on an individual basis. From the 1970s the term 'institutional racism' was deployed to explain how immigrants from Pakistan and the New Commonwealth were becoming a disadvantaged group in the UK. It was suggested that racism could be 'inherent in policy decisions' and yet 'not always recognized by those who devise' those decisions or 'by those who are the recipients' (Allen 1973: 100). The challenge of defining institutional racism and distinguishing it from other forms of racism and from other forms of discrimination has been debated. Diagnosing racism in terms of outcome rather than ideology (Miles 1989) or process (Anthias 1990) was said to make it impossible to ascertain the cause of the disadvantage. Miles (1989) defined institutional racism in terms of structural processes that work independent of the individual's intention, such that intentionality is secondary to the consequences of actions. He suggested that since institutional racism might be 'embodied in exclusionary practices or in a formally non-racialised discourse ... it is necessary to demonstrate the determinate influence of racism' (Miles 1989: 87). In contrast to Miles's attempts to restrict what counted as institutional racism, others have sought to broaden the definition, emphasizing links with exclusions based on class and gender and with other types of racism. Anthias refers to racism, along with ethnicity, as 'discursive, systemic and intersubjective practices and outcomes of social relations which do not emanate exclusively from ethnic or race categories' (1999: para 3.2). This all-encompassing definition has been criticised for the conceptual inflation that renders racism meaningless (Mason 1994, Jenkins 1997). Thus institutional racism is contested in theoretical terms, while there have been few attempts to operationalise, measure or describe it in empirical research and, where this is attempted, the concept has been found wanting (O'Grady et al 2005). The Macpherson report's description of institutional racism as a feature of police work made headlines and was influential in the development of The Race Relations Amendment Act (2000) which required public bodies to produce a race equality policy and action plan. Since then discussions around multiculturalism have shifted to community cohesion and diversity (Pilkington 2008), with the exception of the mental health services, where institutional racism and its role in racialised disparities in mental illness continues to be debated.

\section{Macpherson report's definition of institutional racism}

3.1 In the investigation of Stephen Lawrence's death institutional racism was defined as:
... the collective failure of an organisation to provide appropriate and professional service to people because of their colour, culture or ethnic origin. It can be seen or detected in processes, attitudes and behaviours which amount to discrimination through unwitting prejudice, ignorance, thoughtlessness and racist stereotyping which disadvantage minority people (Macpherson 1999).

3.2 This definition came about through a judicial process, which must refer to precedent for acceptance in the adversarial negotiation between expert witnesses and, in this case, multiple opposed interest groups (Cathcart 1999). Macpherson cited the Scarman report as the only available legal precedent, which had rejected the possibility of institutional racism in the policing of race-related riots in Brixton and Toxteth, but had confirmed 'unwitting racism' as a problem. The Macpherson report found the Metropolitan Police Force to be institutionally racist and called for reform to the National Police Force and other public services. Hailed as a "watershed in British race relations, not least for its official recognition of "institutional racism" (Bridges 2001:61), the report remains a reference point for commentary on and research into the role of racism in civil justice (Bridges 2001, O'Grady et al 2005) and especially the police force (Bennetto 2009, Delsol and Shiner 2006). Although the report's conception of institutional racism has been found deficient for understanding or reforming police work (O'Grady et al 2005, Desol et al 2006), nonetheless it is cited as the authority in critiques of health service provision throughout the UK and beyond, including the US, where it has no formal status (e.g. Griffith et al 2007).

\section{Criticism of the Macpherson definition of institutional racism}

4.1 The Macpherson inquiry was not intended as a scholarly investigation of racism, yet its high profile and 
ongoing citation means that it has been interrogated as such nonetheless (Anthias 1999, Bridges 2001). Criticism of the Macpherson definition of institutional racism has been made in terms of conceptual inflation, the relationship between individual and institution, and the role of intentionality.

\section{Conceptual inflation}

4.2 The Macpherson report's definition of institutional racism suffers from conceptual inflation in its emphasis on outcomes. 'Disadvantage to minority people' is described as a means of identifying institutional racism occurring through 'unwitting prejudice, ignorance, thoughtlessness and racist stereotyping' (Macpherson 1999). The Macpherson definition offers no mechanism to distinguish disadvantage that has accrued to a person of minority ethnicity as a result of class position, gender, employment status or age rather than racism.

\section{Structure and agency: individuals and institutions}

4.3 The report's definition suggests that a person's thoughtlessness may be indicative of institutional racism but how an individual's insensitivity articulates with institutionally discriminatory processes remains unspecified. An individual's 'unwitting racism' is not the same as an organisational process having a racist effect of which individuals may be unaware. The genuinely unwitting racist is unaware of discriminating against a racialised group of people. If, as Miles (1989) suggests, institutional racism concerns organisational procedures which unintentionally discriminate against a racialised minority, the individual's belief, awareness and behaviour regarding racism are irrelevant. The role and responsibility of the individuals who work within discriminatory institutions is the perennial sociological question of structure and agency (Essed 1991). These definitional problems around institutional racism are part of the longer term development of ideas around race. Nineteenth century race thinking relied on a belief in biologically distinct and hierarchically arranged sections of the human species as demonstrated in justifications for apartheid and slavery. 'Race' now refers to a category that may be genetically or culturally constructed and that is not necessarily hierarchical. Race is a difficult concept because it refers to an externally attributed identity associated with prejudice, as well as positively claimed and valued aspects of identity (Bradby and Nazroo 2010). Racism, in its biologically-determined nineteenth century variety is increasingly rare in polite society, let alone public policy, not least because of its legal proscription. Legislation against racism reflects the decreasing acceptability of racist ideas and behaviours such that even the far right British National Party with White supremacist associations, asserts that it is not racist. Since the mid-twentieth century, race has been regarded as a socially constructed concept (Rose, 2007: 156), hence irrelevant to the biological mapping of human diversity (Lewontin 1993, Cooper 1984). How then can concepts of race and racism be defined and used in a way that informs 21 st century service provision? The problem of slippage between previous and current meanings of these terms is exacerbated in a legal context, where authority is determined through precedence. The historical slippage is compounded by the subtlety of distinguishing racism associated with the individual from that associated with the institution.

\section{Intention and the individual}

4.4 Use of the term 'unwitting' in the Macpherson definition raises the problem of intention behind discrimination: mechanisms that might distinguish between discrimination that operates 'wittingly' and 'unwittingly' are not specified (Anthias 1999: para 2.9). The possibility that overt and intentional individual racist beliefs and behaviours could have played a role in determining the course of the investigation of Stephen Lawrence's murder was pursued by the Macpherson inquiry. Despite sustained investigation of documents and cross-questioning of individuals no overt expression of racism could be established. No comparison was drawn with police investigations of White people who died in a violent assault, so the role that the Lawrence family's Blackness played in shaping how the police treated them could not be assessed through a comparative method.

4.5 The difficulties of distinguishing the role of individual, his or her intention and relationship with an institution in the conceptualisation and operation of institutional racism are not novel. Regarding the Scarman report, Mason notes the need for theoretically informed explanations to capture the interconnection of structure and agency, and the term 'institutional racism' as suffering from 'imprecision in many of the formulations of the concept' (1982: 44).

\section{Interpreting the report's findings}

5.1 The Metropolitan Police accepted the Macpherson report's finding that institutional racism was identified in many aspects of the investigation of Stephen Lawrence's murder, including the lack of urgency and commitment of the investigation, the treatment of the Lawrence family and the failure to recognise the murder as racially motivated. Sir lan Blair, Commissioner of the Metropolitan Police, was keen to 
emphasise that accepting the report's findings did not imply that individual officers were racist and that 'this is about organisation, it's not about individuals' (Murji 2007: 849). The emphasis on the organisational nature of the discrimination had the effect of protecting the individuals involved. Dividing the organisation from those who work in it situates individuals conceptually beyond institutions. Blair insisted that the findings did not have any implications for the character of individual police officers, fearing that an implication of individual racism would render law enforcement impossible in parts of London (Cathcart 1999). The attempt to separate the acceptance of institutional racism from any implication of individual racism attributed overbearing influence to the structure, while stripping individuals operating therein of any agency. Such a division severs 'rules, regulations and procedures from the people who make and enact them, as if it concerned qualitatively different racism rather than different positions and relations through which racism operates' (Essed 1991: 36).

5.2 Arguably the most damaging aspect of the investigation was officers' refusal to view the murder as a racist act, insisting that the assault on Stephen Lawrence was ordinary thuggish behaviour. Maintaining this 'colour-blind' attitude meant ignoring witness statements that the white youths who murdered Stephen Lawrence shouted 'nigger' and that the same youths failed to aggress white bystanders (Cathcart 1999, Foster 2008). Officers' failure to see the significance of the Whiteness of the attackers was key to the failure to understand the nature of the crime under investigation. After the insistence on the organisational nature of police racism, secretly filmed material (BBC 2003) showed recruits in three forces making racist comments. Undercover journalism showed individuals in the police force espousing strongly racist views and widespread tolerance of racist banter. More recently it has been suggested that since the Macpherson report, racism is increasingly likely to be covertly expressed (Holdaway and O'Neil 2007). Investigating officers may not have pursued the assault on Stephen Lawrence because they assumed that young Black men are routinely criminally violent such that murder was a 'natural' consequence of his being on the streets of South London. If violence is assumed to be a normal part of day-to-day life for young Black men, then perhaps a violent death is an expected outcome of this 'way of life'. Neville Lawrence, father of Stephen Lawrence, said on day 42 of the inquiry:

It is clear to me that the police come in with the idea that the family of black victims are violent criminals who are not to be trusted. (Macpherson, 1999: page 8131).

5.3 An assumption of the criminality of Black men allows violence to be explained and accepted as the responsibility of the victim. Presuming the inherent criminality of a Black murder victim makes him responsible for his own violent death and leaves the Whiteness of the murderers un-scrutinised. The assumed normativity of Whiteness means that other categories are defined in terms of their deviation from the White category, with the nature of Whiteness rendered invisible (Dyer 1997). The influence of the Lawrence's family's assumed criminality in the investigation of his murder was exposed because Stephen Lawrence had not been involved with violence prior to his murder and came from a respectable, aspirant and law-abiding family who supported his plans to become an architect. Despite the lack of evidence of overt racism, the Macpherson inquiry had to respond to the widely felt sense that a racialised injustice had occurred. The inquiry was conducted in a highly charged atmosphere with the near impossible task of responding to the injustices experienced by the Lawrence family, which resonated with a wider community, as well as a police force on the defensive. In the absence of racists a finding of institutional racism was strategic in retaining racism as a cause of the problem, without needing to prove individual responsibility. The report's finding served its tightly defined legal purpose as well as responding to a broader need for racialised injustice to be addressed. Since then the report's definition of institutional racism has been exported to other contexts, notably the NHS, where its compromised formulation has proven a poor basis for the formation of policies or programmes of political action designed to combat racial disadvantage and oppression (Mason 1982). These problems are illustrated in the report of the investigation into the death of David Bennett.

\section{Minorities and mental health services}

6.1 Since Durkheim's explanation of how social, political, and economic forces produced various types of suicide (Durkheim 1897 (1951)), rates of mental illness have been used as indices of social cohesion. Severe and enduring mental illness represents a form of alienation which, assuming it is reported to the health services, can be measured and quantitatively analysed. Disparities between the mental health of minorities and the general population have been interpreted as reflecting the successful or failed integration of migrants. The direction of the disparity between minority and majority populations in measures of mental illness has not been consistent. During the 1970s and 1980s explanations were sought for low rates of hospital admission for psychological illness among people of South Asian origin (Cochrane et al., 1987, 1989) and low levels of symptoms in community surveys (Cochrane et al., 1977, 1981a, b). South Asian family structure was argued to have a protective effect for symptoms of psychological distress in a version of 'they look after their own'. The healthy migrant effect may have accounted for some of this advantage. 
Since then a consistent picture of poor mental health as well as poor mental health services for some minorities has emerged, characterised by excess rates of illness and detention and poorer pathways to care (Commission for Healthcare Audit and Inspection 2007). The inequalities that disadvantage ethnic minorities and which can be stark, are likely to have complex causes (Sainsbury Centre 2006) and the role which discrimination plays in this complexity is contentious. Excessive use of involuntary detention and persistently excessive rates of acute mental illness have been cited as demonstrating discrimination at work within the system of medical care (McKenzie and Bhui 2007). However, others cite competing hypotheses including diverse patterns of help-seeking to suggest that the evidence that racism causes inequalities is inadequate and contradictory (Singh and Burns 2006). A significant moment in the development of the discourse on institutional racism in the NHS was the report of the inquiry into the death of David Bennett, a Black man with a history of severe and enduring mental illness.

\section{Inquiry into David Bennett's death}

7.1 David Bennett's death while a patient in a medium secure unit (a residential setting where patients are unable to discharge themselves), was subject to an inquiry chaired by Sir John Blofeld (Norfolk, Suffolk and Cambridgeshire Strategic Health Authority 2003). Key witnesses refused to cooperate with the inquiry, but it nonetheless established that Bennett's death was brought about by up to five nurses sitting on him for up to 28 minutes, by which time he had stopped breathing. The events that led up to this excessive restraint included Bennett being racially abused by another patient, his being moved to another ward and his assault of a nurse. These incidents constitute the circumstances of his death, but are insufficient explanation as to why Bennett died since verbal abuse and assault are not uncommon in secure mental health services. The inquiry report described the inequalities in mental health services faced by black and minority patients as 'a festering abscess which is at present a blot upon the good name of the NHS' (Norfolk, Suffolk and Cambridgeshire Strategic Health Authority 2003: 58) and attributed these inequalities to institutional racism (Esmail 2004). The report does not explain how Bennett's death, as a result of the forceful restraint which stopped his breathing, can be related to institutional racism rather than individual prejudice. The Blofeld report found that there was 'insufficient attention paid to' Bennett's 'cultural, social and religious needs', but there was no evidence of 'deliberate racism' from staff (Norfolk, Suffolk and Cambridgeshire Strategic Health Authority 2003: 24). The report states that 'the staff were quite frightened of Bennett because 'of his violence which the staff often saw as unprovoked and because he was a very athletic young man' (Norfolk, Suffolk and Cambridgeshire Strategic Health Authority 2003: 10). Bennett had been a talented footballer, a good musician, playing the drums and a Rastafarian who smoked cannabis (Norfolk, Suffolk and Cambridgeshire Strategic Health Authority 2003: 7). This description suggests the stereotype of Black men as hyper-masculine in terms of strength and as potentially violent could have heightened staff fear. Elsewhere the report describes the very small numbers of Black staff (Norfolk, Suffolk and Cambridgeshire Strategic Health Authority 2003: 24) and patients (Norfolk, Suffolk and Cambridgeshire Strategic Health Authority 2003: 23) in the clinic where Bennett died. The Blofeld report cites the Macpherson report's definition of institutional racism, noting that some people did not appreciate

that unwitting prejudice, ignorance or thoughtlessness or racist stereotyping leads to institutional racism. They considered that institutional racism must be deliberate. (Norfolk, Suffolk and Cambridgeshire Strategic Health Authority 2003: 43).

7.2 The report does not specify who 'they' might be, but does state that 'This is a serious and important misconception which needs to be put right.' Thus the lack of clarity regarding the relationship between individual and institutional racism is both noted and reinforced through citation of the contradictory definition. The assertion that unwitting, ignorant or stereotypical individual acts lead to institutional racism is the only clue the Blofeld report offers as to this relationship. But when do individuals' acts, whether thinking or unthinking, become attributed to the institution? In what sense is it useful to label individually racist acts the responsibility of the institution, except as a means of shedding responsibility? (Institutional racism is ascribed the cause of problems beyond one's own group in a debate between clinicians and the Department of Health described later in this paper). Using institutional racism to explain the circumstances of Bennett's death is problematic. The failure to train staff in methods of safe restraint and prompt resuscitation cannot be seen as institutionally racist in and of itself unless some racist intention or process can be identified in this failure, since all patients could suffer as a consequence. However, if fears of Black male patients' inherent violence led to their being restrained more frequently and forcefully, then a racist effect could ensue. But in this case it is the assumption about Black violence, rather than the failure in training that constitutes the racism in question. Furthermore assumptions about Black violence are held by individuals rather than constituting a feature of the organisation. The embodied moment where nurses sat on Bennett and impeded his breathing by applying excessive restraint cannot easily be connected to features of the organisation unconnected with individual racist belief. If beliefs about Black men's violence constitute institutional racism, then all shared social prejudices may also be regarded 'institutional' rather than 'individual' and the analytic distinction between the two is unclear. 
7.3 Recommendations made to tackle institutional racism reveal further contradictions in the use of the concept. The Blofeld report's number one recommendation is that 'All who work in mental health services should receive training in cultural awareness and sensitivity.' (Norfolk, Suffolk and Cambridgeshire Strategic Health Authority 2003: 67). Racism that has been termed 'institutional' is to be addressed by educating the individual. Similarly, the Macpherson (1999 chapter 47) report's $49^{\text {th }}$ recommendation was 'That all police officers, including CID and civilian staff, should be trained in racism awareness and valuing cultural diversity.'

\section{Racism without a racist}

8.1 Blackness, masculinity and youth were significant features of the circumstances surrounding Lawrence's and Bennett's deaths in that they influenced people's responses to their living and their dead bodies. Such embodied characteristics are not experienced or perceived as disaggregated dimensions of race, gender and age. The lack of diligence with which Lawrence's death was investigated and the excessive force with which Bennett was restrained are partially explained by stereotyped assumptions about young Black men. Health care staff expressed fear of Bennett's violence and athletic strength: the Lawrence family felt that their son's involvement with criminal violence was assumed. This discrimination was not only racist since gender and age and race were all implied. The focus on the young men's race diverted attention from the Whiteness of Lawrence's murderers and of almost all the other staff and patients encountered by Bennett. The official investigations into both deaths heard witnesses assert that racialised difference was an important influence on how the men had been treated. Despite scrutiny neither investigation was able to identify evidence of individual racism from police or healthcare staff. This was a contradictory finding for both investigations: a sense that racism had played some part in shaping events and yet no evidence of a racist. Naming this problem 'institutional racism' allowed the issue of where the racism lay to be obfuscated, avoiding the need to identify individual moments, practices or people as racist. This compromise permitted the accusation of racism to be made publically, since it was levelled at an organisation, without entirely exonerating individuals from responsibility. Both reports maintained the possibility that individuals could be unwittingly racist, which makes sense as a means to partially but not wholly exonerate individuals of responsibility. Neither report interrogated the problematic role of Whiteness as a cultural identity, thereby compounding the under-specified way in which institutional racism was being employed.

\section{Health service inequalities}

9.1 The Blofeld report's assertion of the institutionally racist nature of the NHS was confirmed by evidence of inequality in mental health service use and outcome (Sainsbury Centre for Mental Health 2002, Sashidharan 2003). In response the Department of Health announced a race equality policy (Department of Health 2005) and an audit of rates of psychosis and detention across ethnic groups (Commission for Healthcare Audit and Inspection 2005). These institutional efforts to monitor and reform services may yet be undone by the unacknowledged uncertainty in the role of individuals and organisations in so-called institutional racism. Difficulties defining race and racism so as to inform progressive work, described at the outset of this paper, are exacerbated in medical contexts. Medicine's dominant epistemology supports a tendency to explain difference between ethnic groups in physiological or genetic terms which re-inscribes variation as biologically determined. The centrality of the doctor-patient relationship for medicine's professional claims means that any hint of racism denotes a serious threat (e.g. Singh and Burns (2006) argue that labelling psychiatric services institutionally racist damages trust with Black patients by reinforcing their reluctance to attend). The reform of public services called for after the deaths of Lawrence and Bennett has proven difficult in the criminal justice system and is likely to be at least as difficult in the health and social care system. Severe and enduring mental illness often requires social, educational, employment, housing and medical services, and sometimes the judiciary, police and prison services. Patients and their carers do not necessarily distinguish between teachers, psychologists, lawyers, social workers or doctors involved in their case (Bradby et al 2007). In a patient-centred system, patients would not have to work out these distinctions to make sense of their own care. However, Bennett's family had to unpick the nature of the professional relationships involved in David Bennett's case in the contested setting of an official inquiry, which sat as a result of the pressure that the family had maintained, sometimes against the efforts of uncooperative professionals. The unacceptable nature of racism and the difficulty of defining how individuals and organisations contribute to institutional racism can be seen in arguments between NHS clinicians and managers. Having admitted institutional racism as a feature of the NHS, an anonymous source from the Department of Health stated that 'the solutions lie in the hands of individuals, not institutions' and that the term 'institutional racism' is simply unhelpful (McKenzie and Bhui 2007). The clinicians responded that organisations rather than individuals provide adequate services, such as interpreters or culturally competent therapists, and individuals are neither responsible for the cause of racialised disparities, nor their solution, whereas institutions should 
effective, ethical interventions targeted at delivering equitable services. Unfortunately, when institutions are challenged to do this they often do not take responsibility (McKenzie and Bhui 2007).

9.2 McKenzie and Bhui's comments, directed at 'institutions' are perhaps intended for 'management'. The difficulty in attributing and accepting responsibility for reform indicates a conceptual gap in how institutional racism operates in situ. There is now a presumption (albeit contested) that institutional racism operates in the NHS (Elkan et al 2007). The evidence for the existence of this form of racism is inequality in treatment and outcome that disadvantages ethnic minorities. Programmes to train individual professionals in cultural competency and assess the effects of institutional structures are ongoing (Department of Health 2005). The apparent contradiction of institutional racism being tackled at the level of the individual and the lack of interest in specifying how individual and institutional interact provokes a series of questions. How can policy reform tackle racism that individuals do not espouse, that they may express unwittingly? Are individuals vulnerable to the power of institutions to condition their thoughts? Various forms of cultural awareness training are premised on the idea that when prejudiced people understand the error of their ways, they will reform. However such training can simply redirect the expression of prejudice to a more acceptable idiom. While evidence of direct racism is difficult to detect, White professionals' disapproval of sexism in minority families as the unacceptable face of difference, is not (Bradby et al 2007). Cultural awareness or competency programs tend to focus on minority cultures, thereby leaving implicit the idea that minorities have culture whereas the White majority is made up of rational individuals.

\section{Concluding discussion}

10.1 In the early 1970 s when sociologists started to discuss institutional racism 'race relations' was a contested area of study. The legitimacy of ethnicity and racism as categories for analysis and the need for public service provision to demonstrate efforts to avoid racism is now legally established. However antiracism legislation exists in the context of 'a relative consensual political silence on issues of racism and racial inequality' (Rhodes 2009: 4.2) whereby political discourse recasts racialised inequality in an individualized, culturally-centred discourse to neutralize redistributive claims. What has been referred to as 'apparently benign particularism' (Rhodes 2009: 4.6) is part of a shift away from structural explanations of inequality towards an emphasis on culture (Pilkington 2008). The absence of institutional explanations for exclusion and discrimination in wider political discourse perhaps explains why the assertion of institutional racism in mental health services co-exists with so little sociological commentary or sense of how this discrimination works. 10.2 The assumption that institutional racism is responsible for ethnic mental health inequalities has made it difficult to interrogate how institutional processes discriminate around race, gender, age and other categories. Without a grasp of how discrimination operates within institutions, policy seeking to reduce racialised inequalities will continue to fall back on educating individuals even (perhaps especially) when they claim not to be racist. Education that ignores Whites as a cultural or ethnic category compounds some of the inequalities that the Macpherson and Blofeld reports describe. In the longer term the failure of current initiatives to reduce inequalities, particularly with a Black president in the White House, may lead to the ill-founded presumption that the inequalities attributed to institutional racism are no longer a problem. The prominence of institutional racism in mental health policy can be related to the impact of the death of Bennett after institutional racism had been raised as a prospect by the Macpherson report. The shift in the meaning of institutional racism in mental health policy has so far attracted very little sociological attention, perhaps because of the longstanding assumption that medical sociology is a theoretically uninteresting field (Cockerham 2001). 10.3 Institutional racism is currently loaded with meaning which cannot necessarily be clarified with reference to sociological theories of racism because events have over-taken those theories. In its 1970s guise institutional racism referred to organisational features operating independent of the individual, but this no longer pertains. What is now indicated by 'institutional racism' implies individuals and their gendered, age-inflected racism as well as the way that they act as representatives and agents of an institution and wider society. The term institutional racism could also be taken as referring to the tendency to ignore Whites as an ethnic or cultural group, compounding minority culture as the cause of the problem when faced with racialised inequalities. These changes in the way that institutional racism is used as a term should provoke a sociological response and some suggestions are made here. First, a return to sociological conceptulisations of racism to see how they are manifest in mental health services might be warranted. Certainly, we know very little about how racism operates in the NHS and have not attended to Miles's (1989) call to establish the determinate influence of racism in institutional processes. Second, conceptualisations may need to be overhauled in the light of current evidence. This sociological distinction between individual and institution and the focus on the conscious rational individual is unhelpful in understanding current public discourse on institutional racism. An assumption of individuals' rational consciousness should be re-assessed in a public service setting. Richard Jenkins credits Bourdieu with an implicit recognition that the distinction between conscious thought and unconscious mind is not a sharp separation and that this is 'likely to be the source of the potency of processes of institutionalization' (2002: 179). The strength of the shared cultural denigration of 'mad Black 
men' may render prejudice more than usually available to inform processes of institutionalisation. Cognitive social psychology has been pursuing this possibility with research into unconscious bias in interpersonal medical communication (e.g. Stivers and Majid 2007). This research has reformative possibilities when applied to strategic training programmes that could reduce unconscious stereotyping among health professionals (Burgess et al 2007). Third and relatedly, is the need, noted elsewhere, to include Whites as a category in thinking about racialisation so as to tackle what has been termed 'colour blind racism' (Bonilla-Silva 2006). Fourth and having over-hauled what is implied by institutional racism, an examination of how racism became institutionalised in the NHS would illuminate both the development of sociological concepts and the ways in which social psychological interventions can be best deployed. The post-World War II cohort of migrants who undertook posts in settings rejected by White health care professionals, are currently reaching the end of their working lives (Taylor and Esmail 1999). These medical migrants probably played a crucial but un-remarked upon role integrating their fellow migrants into the health care system as well as being themselves subject to discrimination (Kyriakides and Virdee 2003), while their own prejudices would have been influential in establishing how racialised minorities were treated in the NHS. Soon this cohort will reach the end of their lives, as well as their NHS careers. Their accounts are key evidence of how racism became unacceptable over the twentieth century and yet did not disappear; how racism came to operate independently of racists. 10.4 The anthropologist Marshall Sahlins observed that 'Events are ordered by culture, $\ldots$ in that process, the culture is reordered' (1981: 8). The search for single variables that explain difference combined with historically racialised thinking has made it difficult to escape a rather simplistic approach. In the case of mental health inequalities this has led to embattled positions where racism, behavioural factors or socioeconomic deprivation have all too often been seen as alternative causative hypotheses and painstaking documentation of complex interactions has been avoided. Since both race and mental health are subject to the classificatory struggle for meaning, that struggle is part of the understanding of inequality. The endless tension between showing inequality by measuring it and reinforcing the categories of differentiation (Bradby 2003) is part of the classificatory struggle. Intuitively, the epidemiological disadvantage and the unsatisfactory communication that Black patients experience appear linked, but we have no model of how this might work that can be operationalised in empirical research. David Bennett's story (and those of other Black patients (Sainsbury Centre for Mental Health 2002)), suggests that discriminatory processes accrue over a lifetime and their effect cannot be read off, for instance at the moment when psychiatric staff restrict a man's breathing through excessive restraint. Until the macro, micro and long-term processes of racism can be conceptualised together we leave clinicians, managers and policy-makers arguing about responsibility.

\section{Notes}

${ }^{1}$ At the time of writing (March 2010) the Democrats have just welcomed the approval of the bill that will extend healthcare to citizens who are currently uninsured.

\section{Acknowledgements}

Thanks to all of the anonymous referees who have made comments on previous drafts of this paper.

\section{References}

ALLEN, S. (1973) 'The Institutionalization of Racism.' Race and Class 15: 99-106. doi: 10.1177/030639687301500106. [doi:10.1177/030639687301500106]

ANTHIAS, F. (1990) 'Race and Class Revisited: Conceptualising Race and Racisms.' Sociological Review, 38(1): 19-42. [doi:10.1111/j.1467-954X.1990.tb00846.x]

ANTHIAS, F. (1999) 'Institutional Racism, Power and Accountability'. Sociological Research Online, 4: 1. <http://www.socresoline.org.uk./4/lawrence/anthias.html> [doi:10.5153/sro.239]

BENNETTO, J. (2009) 'Police and Racism: What has been achieved 10 years after the Stephen Lawrence inquiry report?' London: Equality and Human Rights Commission.?

<http://www.equalityhumanrights.com/uploaded_files/raceinbritain/policeandracism.pdf>

BBC (2003) The Secret Policeman, broadcast Tuesday 21st October <

http://news.bbc.co.uk/1/hi/uk/3203287.stm>

BONILLA-SILVA, E. (2006). Racism Without Racists: Color-Blind Racism and the Persistence of Racial Inequality in the United States. New York: Rowman \& Littlefield. 
BURGESS, D., VAN RYN, M., DOVIDIO, J. and SAHA, S. (2007) 'Reducing racial bias among health care providers: lessons from social-cognitive psychology.' Journal of General Internal Medicine , 22, 6, 882-887. [doi:10.1007/s11606-007-0160-1]

BRADBY, H. (2003) 'Describing ethnicity in health research' Ethnicity and Health 8(1) 5-13.

[doi: 10.1080/13557850303555]

BRADBY, H. and NAZROO, J. (2010) 'Health, ethnicity and race' pg 113-129 in William C Cockerham (ed.) The New Companion to Medical Sociology Malden MA: Blackwell.

BRADBY, H., VARYANI, M., OGELTHORPE, R., RAINE, W., WHITE, I. and MINNIS. H. (2007) 'British Asian families and the use of child and adolescent mental health services: a qualitative study of a hard to reach group.' Social Science and Medicine 65(12) 2413-24. [doi:10.1016/j.socscimed.2007.07.025]

BRIDGES, L. (2001) 'Race, law and the state.' Race And Class 43(2), 61 - 76. [doi:10.1177/0306396801432005]

CARMICHAEL, S. and HAMILTON, C.V. (1969) Black Power: the politics of liberation in America . Harmondsworth: Penguin.

CATHCART, B. (1999) The Case of Stephen Lawrence. London: Viking.

COCHRANE, R. and STOPES-ROE, M. (1977) 'Psychological and social adjustment of Asian immigrants to Britain: a community survey.' Social Psychiatry 2: 195-206. [doi:10.1007/BF00578139]

COCHRANE, R. and STOPES-ROE, M. (1981a) 'Psychological symptom levels in Indian immigrants to Britain: a community survey.' Psychological Medicine 2: 319-327. [doi:10.1017/S0033291700052132]

COCHRANE, R. and STOPES-ROE, M. (1981b) 'Psychological symptom levels in Indian immigrants to England - a comparison with native English.' Psychological Medicine 2: 319-327.

[doi:10.1017/S0033291700052132]

COCHRANE, R. and BAL, S.S. (1987) 'Migration and schizophrenia: an examination of five hypotheses.' Social Psychiatry 2: 181-191. [doi:10.1007/BF00583553]

COCHRANE, R. and BAL, S.S. (1989) 'Mental hospital admission rates of immigrants to England: a comparison of 1971 and 1981.' Social Psychiatry and Psychiatric Epidemiology 2: 2-11.

[doi:10.1007/BF01788193]

COCKERHAM, W.C. (2001) Medical Sociology and Sociological Theory. Pages 3-22 in The Blackwell Companion to Medical Sociology. Ed William C Cockerham. Malden MA: Blackwell.

COMMISSION FOR HEALTHCARE AUDIT AND INSPECTION (2007) Count me in. Results of the 2006 national census of inpatients in mental health and learning disability services in England and Wales.

London: Commission for Healthcare Audit and Inspection.

<http://www.cqc.org.uk/_db/_documents/Count_Me_In_2006.pdf>

COMMISSION FOR HEALTHCARE AUDIT AND INSPECTION (2005) Count me in. Results of a national census of inpatients in mental health hospitals and facilities in England and Wales. London: Commission for Healthcare Audit and Inspection.

<http://www.psychminded.co.uk/news/news2005/dec05/Countmein.pdf>

COOPER, R. (1984) 'A note on the biologic concept of race and its application in epidemiologic research. American Heart Journal, 2, 715-723. [doi:10.1016/0002-8703(84)90662-8]

DEPARTMENT OF HEALTH (2005) Delivering race equality in mental health care: an action plan for reform inside and outside services and the government's response to the independent inquiry into the death of David Bennett. London: Department of Health.

<http://www.dh.gov.uk/assetRoot/04/10/07/75/04100775.pdf>

DELSOL, R. and SHINER, M. (2006) 'Regulating stop and search: a challenge for police and community relations in England and Wales.' Critical criminology 14: 241-263. doi: 10.1007/s10612-9013-1

[doi:10.1007/s 10612-006-9013-1]

DURKHEIM, E. (1897 (1951)) Suicide: A Study in Sociology. New York: The Free Press.

DYER, R. (1997) White: Essays on Race and Culture. London: Routledge. 
ELKAN, R., AVIS, M., COX, K., WILSON, E., PATEL, S., MILLER, S., DEEPAK, N., EDWARDS, C., STANISZEWSKA, S. and KAI, J. (2007) 'The reported views and experiences of cancer service users from minority ethnic groups: a critical review of the literature.' European Journal of Cancer Care 16 (2): 109121.

ESSED, P. (1991) Understanding Everyday Racism . London: Sage.

ESMAIL, A. (2004) 'The prejudices of good people.' British Medical Journal . June 19; 328(7454): 1448 -1449. doi: $10.1136 / \mathrm{bmj} .328 .7454 .1448$.

FOSTER, J. (2008) 'It might have been incompetent, but it wasn't racist': murder detectives' perceptions of the Lawrence Inquiry and its impact on homicide investigation in London.' Policing and Society 18 (2): 89 112. [doi: $10.1080 / 10439460802008579$ ]

GRIFFITH, D.M., MASON, M., YONAS, M., ENG, E., JEFFRIES, V., PLIHCIK, S. and PARKS, B. (2007) 'Dismantling institutional racism: theory and action.' American Journal of Community Psychology 39:381 -392. doi: 10.1007/s10464-007-9117-0

HOLDAWAY, S. and O'NEILL, M. (2007) 'Where has all the racism gone? Views of racism within constabularies after Macpherson.', Ethnic and Racial Studies 30 (3): 397- 415.

[doi:10.1080/01419870701217480]

JENKINS, R. (1997) Rethinking Ethnicity. London: Sage.

JENKINS, R. (2002) Pierre Bordieu. 2nd edition. Routledge: Abingdon.

KYRIAKIDES, C. and VIRDEE, S. (2003) 'Migrant Labour, Racism and the British National Health Service.' Ethnicity and Health 8(4): 283-305. [doi:10.1080/13557850310001631731]

LEWONTIN, R.C. (1993) The Doctrine of DNA . London, Penguin.

MACPHERSON, W. (1999) The Stephen Lawrence Inquiry: report of an inquiry by Sir William Macpherson of Cluny. London. Home Office Cm 4262-I. <http://www.archive.officialdocuments.co.uk/document/cm42/4262/4262.htm>

MCKENZIE, K. and BHUI, K. (2007) 'Better mental healthcare for minority ethnic groups - moving away from the blame game and putting patients first: Commentary on Institutional racism in psychiatry.' Psychiatric Bulletin 31: 368-369. doi: 10.1192/pb.bp.107.017145 [doi:10.1192/pb.bp.107.017145]

MCKENZIE, K. and BHUI, K. (2007) 'Editorial: Institutional racism in mental health care.' British Medical Journal 334: 649-650 (31 March). doi: 10.1136/bmj.39163.395972.80

MASON, D. (1982) 'After Scarman: A Note on the Concept of Institutional Racism.' New Community X(1): 38-45.

MASON, D. (1994) 'On the Dangers of Disconnecting Race and Racism.' Sociology 28(4): 845 - 859. [doi:10.1177/0038038594028004003]

MILES, R. (1989) Racism. London Routledge.

MURJI, K. (2007) 'Sociological Engagements: Institutional Racism and Sociology.' Sociology 41(5): 843-55. doi: $10.1177 / 0038038507080440$ [doi:10.1177/0038038507080440]

NORFOLK, SUFFOLK AND CAMBRIDGESHIRE STRATEGIC HEALTH AUTHORITY (2003) Independent inquiry into the death of David Bennett. Norfolk, Suffolk and Cambridgeshire Strategic health Authority. <http://image.guardian.co.uk/sys-files/Society/documents/2004/02/12/Bennett.pdf>

O'GRADY, A., BALMER, N., CARTER, B., PLEASENCE, P., BUCK, A. GENN, H. (2005) 'Institutional Racism and Civil Justice.' Ethnic and Racial Studies , 28(4): 620 - 628. [doi:10.1080/01419870500092514]

PILKINGTON, A. (2008) 'From institutional racism to community cohesion: the changing nature of racial discourse in Britain.' Sociological Research Online, 13 (1) <http://www.socresonline.org.uk/13/3/6.html>

RHODES, J. (2009) 'Revisiting the 2001 Riots: New Labour and the Rise of 'Colour Blind Racism." Sociological Research Online 14 (5) <http://www.socresonline.org.uk/14/5/3.html> [doi:10.5153/sro.2048]

ROSE, N. (2007) The Politics of Life Itself . Princeton: Princeton University Press. 
SAINSBURY CENTRE FOR MENTAL HEALTH (2002) Breaking the circles of fear: a review of the relationship between mental health services and African and Caribbean communities. London: Sainsbury Centre for Mental Health. <http://www.centreformentalhealth.org.uk/pdfs/Breaking_the_Circles_of_Fear.pdf>

SAINSBURY CENTRE FOR MENTAL HEALTH (2006) Policy Paper 6: The Costs of Race Inequality . London: Sainsbury Centre for Mental Health.

<http://www.centreformentalhealth.org.uk/pdfs/costs_of_race_inequality_policy_paper_6.pdf>

SAHLINS, M. (1981) Historical methaphors and mythical realities . Ann Arbour: University of Michigan Press.

SASHIDHARAN, S.P. (2003) Inside Outside: Improving mental health services for black and minority ethnic communities in England. London: Department of Health.

SINGH, S.P. and BURNS, T. (2006) 'Race and mental health: there is more to race than racism.' British Medical Journal 333: 648-651 (23 September). doi:10.1136/bmj.38930.501516.BE

STIVERS, T. and MAJID, A. (2007) 'Questioning Children: Interactional Evidence of Implicit Bias in Medical Interviews.' Social Psychology Quarterly 70 (4): 424-441. [doi:10.1177/019027250707000410]

TAYLOR, D.H. and ESMAIL, A. (1999) 'Retrospective analysis of census data on general practitioners who qualified in South Asia: who will replace them as they retire?' British Medical Journal. January 30; 318(7179): 306-310. 